\title{
Can Factor Analysis be Applied to Spectra Taken in Binary Solvent Mixtures?
}

\author{
Thalyta S. Thurler, ${ }^{a}$ Raquel G. S. da Souza, ${ }^{a}$ Marcel Maeder, ${ }^{b}$ Sarah E. Norman ${ }^{b}$ and Ira M. Brinn ${ }^{*, a, \#}$ \\ ${ }^{a}$ Instituto de Química, Universidade Federal do Rio de Janeiro, Ilha do Fundão, CP 68.563, \\ 21945-970 Rio de Janeiro-RJ, Brazil \\ ${ }^{b}$ Department of Chemistry, University of Newcastle, Callaghan, NSW, 2308, Australia
}

\begin{abstract}
Sugere-se aqui que, apesar das inconsistências lógicas, o método de análise fatorial pode ser aplicado, em muitos casos, aos espectros de fluorescência e absorção de sistemas de corantes em solventes binários. Os limites para a aplicação bem sucedida do método são derivados. A idéia foi aplicada aos sistemas de quatro corantes em duas soluções diferentes de solvente binário. Os resultados obtidos indicaram que este método geralmente gerava curvas mais lisas, num gráfico de contribuição de uma das duas bandas contribuintes aos espectros experimentais contra a fração molar de um dos solventes, quando comparado com o método normalmente utilizado de graficar a posição do pico máximo contra a fração molar de um dos solventes.
\end{abstract}

It is suggested that, in spite the logical inconsistencies, factor analysis can be applied in many cases to fluorescence and absorption spectra of dyes in binary solvent mixtures. Limits as to when this application will be successful are derived. This idea was applied to four different dyes in two different binary solvent mixtures and was generally found to generate smoother curves, plotting the contribution of one of the two contributing bands to the experimental spectrum vs. solvent component mole fraction, as compared to those that are generated when one uses the normally applied method of plotting maximum peak position vs. solvent component mole fraction.

Keywords: binary solvents, factor analysis, absorption spectra, fluorescence spectra

\section{Introduction}

Although the great majority of studies of solutions in the chemical laboratory are done on solutes dissolved in pure (to the extent that they can be attained practically) solvents, most solutions encountered in nature are considerably more complex. Thus, the importance of studying binary (and higher order) solvent systems is obvious. A major question which comes up in these studies is to what extent is there preferential solvation by one of the solvents, which can be related to the specific solute-solvent and solvent-solvent ${ }^{1}$ interactions as well as dipole-dipole interactions, the latter being quite general. These are measured most often by plotting curves of some spectroscopic ${ }^{2}$ property (maximum wavelength, peak height, etc.) of an added probe against mole fraction of one of the solvents. However, the apparent

*e-mail: irabrinn@iq.ufrj.br

"Present address: Natural Sciences, Health and Wellness, Miami Dade College, 300 N. E. $2^{\text {nd }}$ Avenue, Miami Florida, 33132 USA interpretation of the data often varies ${ }^{3}$ with the particular spectroscopic property and molecular probe used. This is not surprising, as each spectroscopic property is affected in a different manner by the solute-solvent interactions. In addition, when using fluorescence spectroscopy, as compared to normal electronic absorption spectroscopy, time-dependent ${ }^{4}$ behavior must sometimes be considered. An alternative approach that has been applied ${ }^{5}$ is to eliminate the probe molecule and study the vibrational spectra of one of the solvents, either through Raman or infrared spectroscopy. Such methods are more limited in that they furnish only information on solvent-solvent interactions, however not solute-solvent interactions.

In order to model solute-solvent interactions and their effect on spectroscopic properties, let us consider first the trivial case of a single solute species, $\mathrm{X}$, in the pure solvent, A. In general, the electronic absorption and fluorescence spectra of this system will be defined by the energy separations of the vibronic levels of the $S_{0}$ and $S_{1}$ states. These, in turn, are defined by the effect of solute-solvent 
$(\mathrm{X} \cdots \mathrm{A})$ interactions on the energy levels of $\mathrm{X}$. Changing to another pure solvent, B, will, in general, shift the position of the spectra, due to different solvent-solute interactions. We now consider the spectra of $\mathrm{X}$ in mixtures of $\mathrm{A}$ and $\mathrm{B}$.

There are two possible models that can be used to describe the solvation in these mixtures. In the simpler model, it can be considered that each absorbing or emitting $\mathrm{X}$ is completely surrounded either by A molecules or by $\mathrm{B}$ molecules. The spectrum observed should then be a linear combination of the two spectra, $\mathrm{X}$ in pure $\mathrm{A}$ and $\mathrm{X}$ in pure $B$. And applying factor analysis to a series of these spectra should generate the two deconvoluted spectra characteristic of $\mathrm{X}$ in the pure solvents and the fractional contribution of each in each of the experimental spectra. This model suffers from the fact that it is not expected to be the general case, even though it might hold for certain data sets.

The second model considers that, in solvent mixtures, solvation of $\mathrm{X}$ will be through a large distribution of combinations of A and B. This distribution should reflect the concentration of solvents in the bulk solution and the relative solvation energies of $\mathrm{X}$ in the two solvents. In this case the experimentally determined spectra will be a linear combination of a large number of $\mathrm{X}(\mathrm{A})_{\mathrm{n}}(\mathrm{B})_{\mathrm{m}}$ combinations, where for any given combination of $n$ and $m$ there may be several distinct possible spectra due to permutation of the solvent positions. This second model is obviously the general case, however, under certain conditions, it is possible to adequately describe the electronic spectra of these systems as a linear contribution of only two spectra. What follows describes these conditions.

Consider the emission spectrum of the solute in a pure solvent to be adequately described by a single Gaussian, which can be given by

$$
I(\bar{v})=c \exp \left[-\alpha\left(\bar{v}-\bar{v}_{0}\right)^{2}\right]
$$

where I is the emission intensity at $\bar{v}$ (in wavenumbers), $\bar{v}_{0}$ is the location of the maximum of the band, and $\alpha$ is given by

$$
\alpha \equiv 4 \ln (2) / \mathrm{f}^{2}
$$

where $\mathrm{f}$ is the full width at half amplitude and $\mathrm{c}$ is a linear parameter defining the emission intensity.

If the emission spectrum in any solvent mixture can be expressed as a linear combination of the emission spectra in each pure solvent

$I(\bar{v})=c_{1} \exp \left[-\alpha\left(\bar{v}-\bar{v}_{0, A}\right)^{2}\right]+c_{2} \exp \left[-\beta\left(\bar{v}-\bar{v}_{0, B}\right)^{2}\right](3)$

$c_{1}$ and $c_{2}$ are related to the solvent composition but not necessarily in a simple function. Arbitrarily assuming $\bar{v}_{0, \mathrm{~B}}>\bar{v}_{0, \mathrm{~A}}$ (which involves no loss of generality) and that $\alpha=\beta$ (i.e., the two emission bands are of equal widths, generates

$\mathrm{I}(\bar{v})=\mathrm{c}_{1} \exp \left[-\alpha\left(\bar{v}-\bar{v}_{0, \mathrm{~A}}\right)^{2}\right]+\mathrm{c}_{2} \exp \left[-\alpha\left(\bar{v}-\bar{v}_{0, \mathrm{~B}}\right)^{2}\right](4)$

For the intensity given in equation 4 to look like the experimental emission curve in a solvent mixture it should have the appearance of a Gaussian. This implies that I $(\bar{v})$ cannot have a minimum between the two maxima at $\bar{v}_{0, \mathrm{~A}}$ and $\bar{v}_{0, \mathrm{~B}}$. To localize all minima in equation 4 we can calculate the first derivative

$$
\begin{aligned}
& \mathrm{d} \mathrm{I}(\bar{v}) / \mathrm{d} \bar{v}=-2 \alpha\left\{\mathrm{c}_{1}\left(\bar{v}-\bar{v}_{0, \mathrm{~A}}\right) \exp \left[-\alpha\left(\bar{v}-\bar{v}_{0, \mathrm{~A}}\right)^{2}\right]+\right. \\
& \left.\mathrm{c}_{2}\left(\bar{v}-\bar{v}_{0, \mathrm{~B}}\right) \exp \left[-\alpha\left(\bar{v}-\bar{v}_{0, \mathrm{~B}}\right)^{2}\right]\right\}
\end{aligned}
$$

and observe its zeros. It can be shown that the values of $\alpha$ which generate no minima in the interval between $\bar{v}_{0, \mathrm{~A}}$ and $\bar{v}_{0, \mathrm{~B}}$, independent of $\mathrm{c}_{1}$ are

$\alpha \leq 4 \ln 2$

or

$\mathrm{f} \geq \overline{\mathrm{v}}_{0, \mathrm{~B}}-\overline{\mathrm{v}}_{0, \mathrm{~A}}$

i.e., the bands are wider than their maximal spectral shifts.

This condition is relatively easy to satisfy, as $f$ values are commonly in the order of $3000 \mathrm{~cm}^{-1}$, whereas solvatochromic shifts usually are not much greater than $2000 \mathrm{~cm}^{-1}$. In addition, through a judicious choice of solvents A and B, this condition can always be met.

Fluorescence spectra which cannot be adequately described as a single Gaussian can be treated in a similar manner, albeit they will almost certainly give inferior fits. In the case of these more complicated bands many more parameters would have to be defined and a simple analytical treatment, such as given above, would not be possible.

What follows is a series of factor analyzed spectra of four different strongly fluorescent dyes in two different solvent binary mixtures, i.e., chloroform/2-propanol and acetonitrile/ethyl acetate.

\section{Experimental}

\section{Preparation of chemicals}

The dyes used (Figure 1) were 2,2,8,8-tetramethyl3H,7H-di-1,4-pyran[3,2-c,1]dibenzo[e,j]phenazine (DPZ6c), 2,2-dimethyl-3H-furan[3,2-c]benzo[e]phenazine 


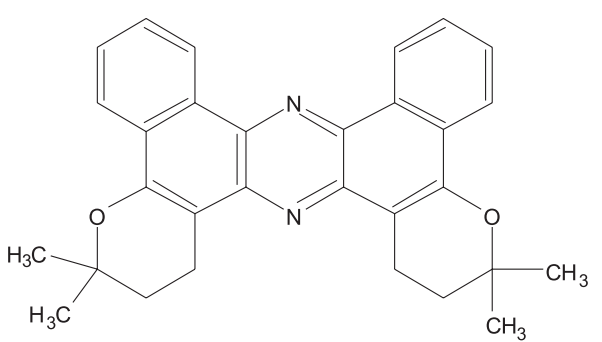

a

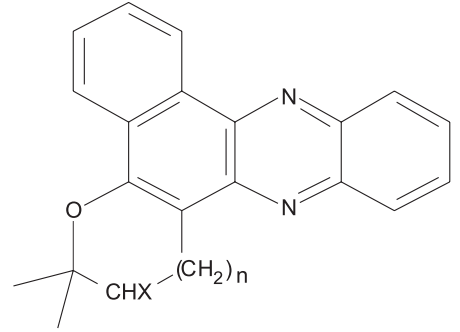

b

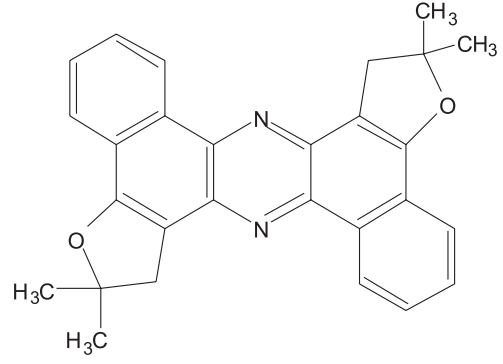

C

Figure 1. Molecular structures; a) DPZ6c, b) PZ5 $(n=0, X=H)$, and PZ6Br $(n=1, X=B r)$, and c) DPZ5t.

(PZ5), 2,2-dimethyl-3-Br-1,4-pyran[3,2-c]benzo[e] phenazine $(\mathrm{PZ6Br})$ and 2,2,10,10-tetramethyl-1H,9Hdifuran[3,2-c,j]dibenzo[e,1]phenazine (DPZ5t), which were prepared and purified as previously ${ }^{6}$ given. The absorption and fluorescence spectra peak maxima in various pure solvents, including chloroform (Chl), 2-propanol (2Prop)

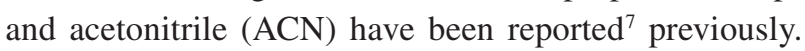
The dye concentration used for the absorption spectra was typically between $10^{-5}$ and $10^{-4} \mathrm{~mol} \mathrm{~L}^{-1}$ and in the order of $2 \times 10^{-5} \mathrm{~mol} \mathrm{~L}^{-1}$ for the fluorescence spectra. The solvents used for this study were Chl, 2Prop and Ethyl Acetate (EtAc) (Merck, Spectroscopic grade) and ACN (Merck, for chromatography). Any $\mathrm{HCl}$ that may have formed in the chloroform was eliminated immediately prior to using by the addition of $\mathrm{Na}_{2} \mathrm{CO}_{3}$. The other three solvents were used as received.

\section{Absorption spectroscopy}

Absorption spectra were taken on a Analytic Jena Second 210 spectrophotometer. Starting with a solution of one of the dyes in one of the pure solvents, the second solvent of the pair was added continuously until equal volumes of the two solvent in the binary mixture was attained. The experiment was then repeated, starting with the dye in the second solvent and titrating with the first solvent to the same point of equal volumes. Absorption spectra over a range of $120 \mathrm{~nm}$ with a spectral resolution of $1 \mathrm{~nm}$ were taken. More than 100 spectra were generated, composing the entire set of spectra of any given dye in either of the solvent mixtures, of which over 30 spectra were used in the application of factor analysis.

\section{Fluorescence spectroscopy}

Fluorescence spectra were taken on a Hitachi F-4500 Spectrofluorimeter and not corrected for instrumental sensitivity. Eleven different binary solutions were prepared, varying the volume per cent of the second solvent at intervals of $10 \%$. The eleven (uncorrected) fluorescence spectra of each set were recorded at intervals of $0.2 \mathrm{~nm}$, over a range of $100 \mathrm{~nm}$.

\section{Factor analysis}

Factor analysis was done utilizing the Self-Modeling Factor Analysis method ${ }^{8}$ in a locally written program ${ }^{9}$ that has been shown ${ }^{10}$ to be capable of successfully removing statistical noise. The method analyzes a set of normalized (to the same area $=1.0$ ) spectra as an eigenvalue-eigenvector problem, in which the calculated contributing spectra are derived from the eigenvectors and the corresponding eigenvalues represent the contribution of the calculated spectra to the experimental spectra. In all cases only the two calculated spectra with the highest eigenvalues were maintained and linear combinations of these two normalized calculated spectra were fitted to all of the normalized experimental spectra of the set. This process is optimized by calculating the point-by-point square of the deviations (ssq) of the calculated and experimental spectra.

\section{Results and Discussion}

Figures 2 through 7 show, side by side, for the four dyes studied here, the variation in the wavelength at maximum intensity $\left(\lambda_{\mathrm{MAX}}\right)$ compared to the variation of the contribution of one of the factor analysis calculated contributing spectra (FA con), as a function of $\chi_{2 \text { Prop }}$ (in the $\mathrm{CHCl}_{3} / 2$-propanol mixtures) and as a function of $\chi_{\mathrm{ACN}}$ (in the ethyl acetate/acetonitrile mixtures). In the cases of the dyes DPZ6c and PZ6Br both the absorption and fluorescence spectra were treated, whereas in the cases of DPZ5t and PZ5 only the absorption spectra were taken.

The maxima of the two calculated spectra making the greatest contributions to the experimental spectra, according to the factor analysis calculations are shown in Table 1. A reasonable measure of the goodness of fit, using a linear combination of the two calculated contributing 


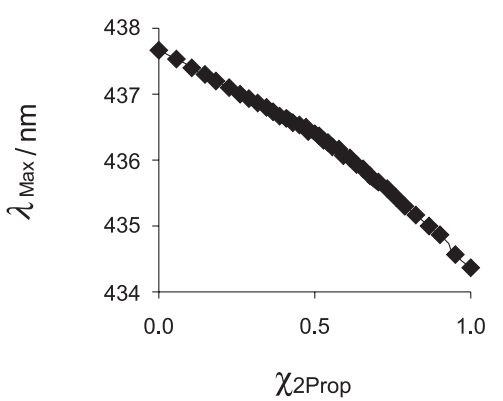

Absorption - a

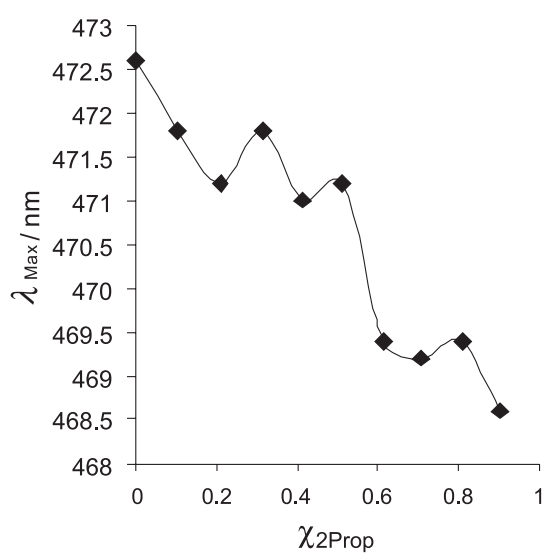

Fluorescence Emission - a

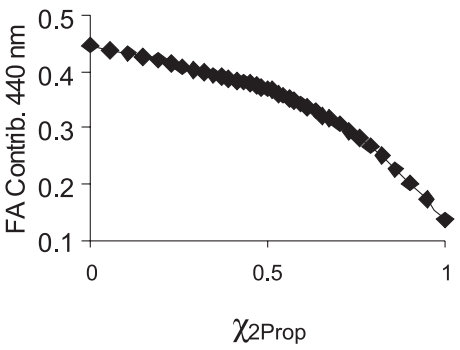

Absorption - b

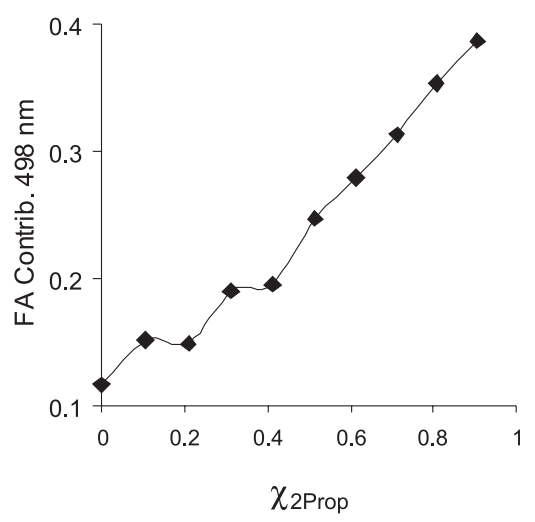

Fluorescence Emission - $b$

Figure 2. Spectral results of DPZ6c in Chloroform/2-Propanol binary mixtures as function of mole fraction of 2-propanol. a) band maximum and b) factor analysis calculated contribution of first of two calculated spectral bands; $434 \mathrm{~nm}$ (Abs.) and $498 \mathrm{~nm}$ (Fluor.).

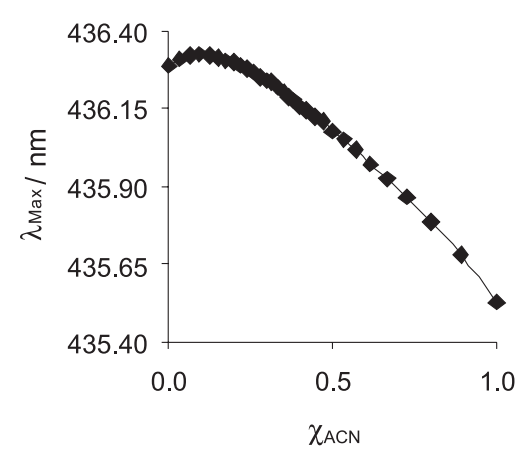

Absorption - a

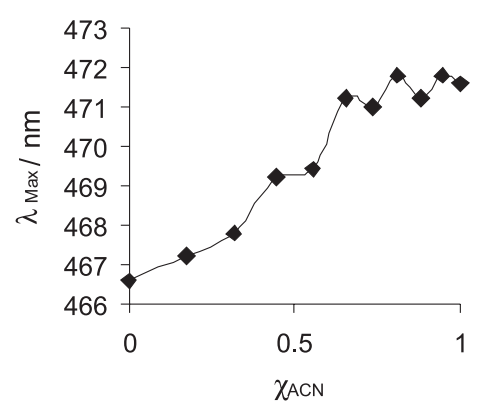

Fluorescence Emission - a

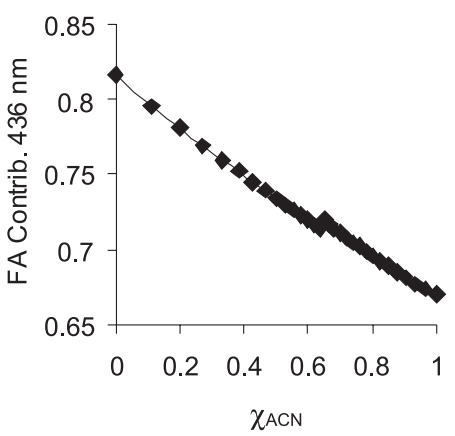

Absorption - b

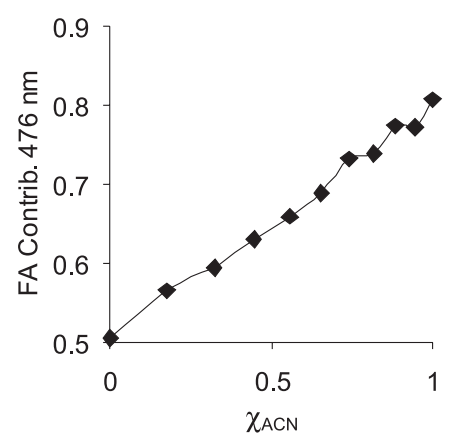

Fluorescence Emission - $b$

Figure 3. Spectral results of DPZ6c in Ethyl Acetate/Acetonitrile binary mixtures as a function of mole fraction of Acetonitrile. a) band maximum and b) factor analysis calculated contribution of first of two calculated spectral bands; $436 \mathrm{~nm}$ (Abs.) and $476 \mathrm{~nm}$ (Fluor.). 


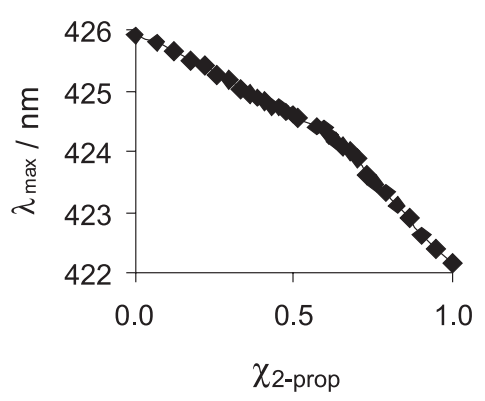

Absorption - a

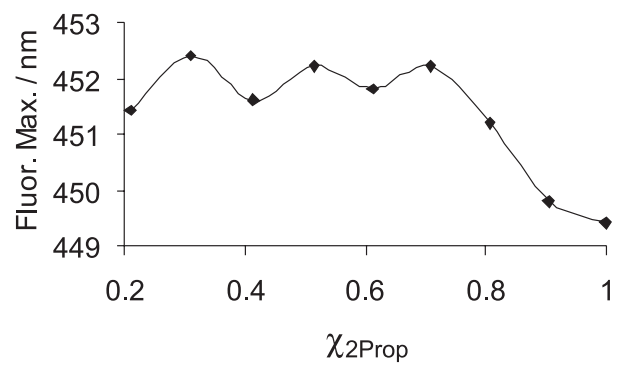

Fluorescence Emission - a

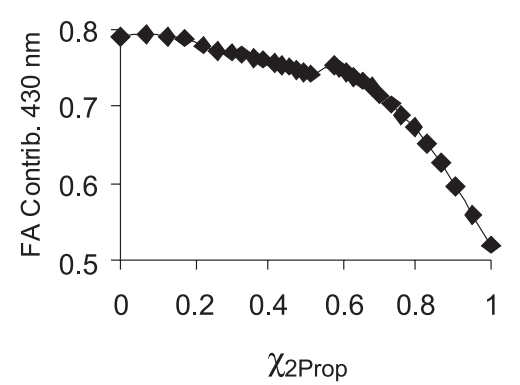

Absorption - b

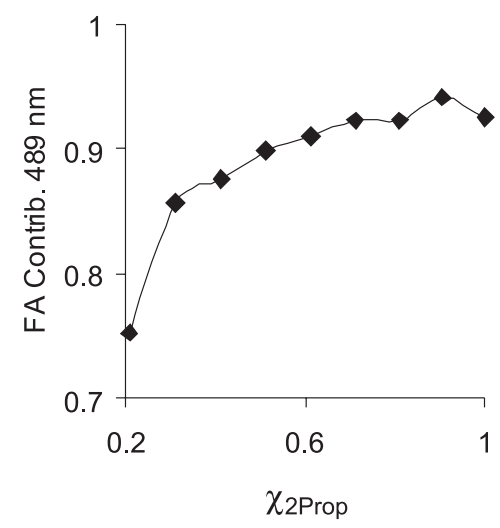

Fluorescence Emission - b

Figure 4. Spectral results of PZ6Br in Chloroform/2-Propanol binary mixtures as a function of mole fraction of 2-propanol. a) band maximum and b) factor analysis calculated contribution of first of two calculated spectral bands; $430 \mathrm{~nm}$ (Abs.) and $489 \mathrm{~nm}$ (Fluor.).

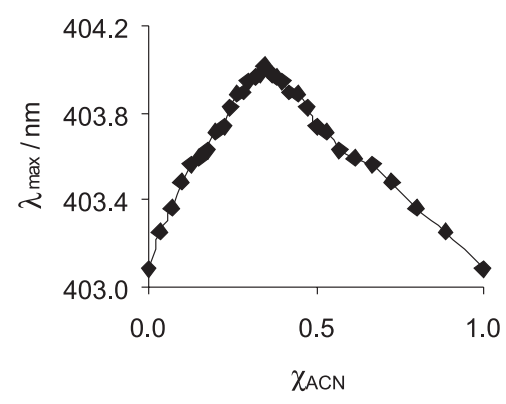

Absorption - a

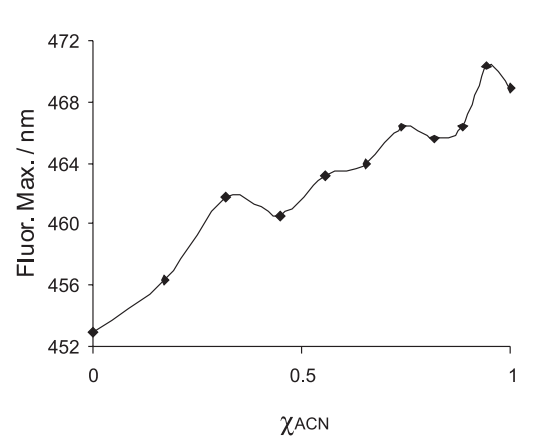

Fluorescence Emission - a

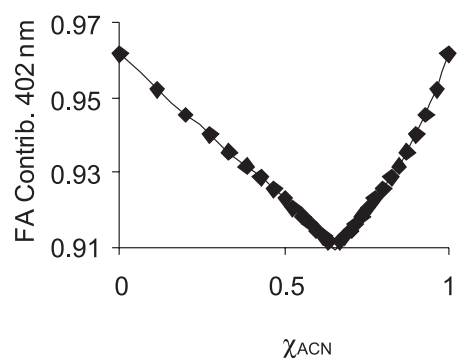

Absorption - b

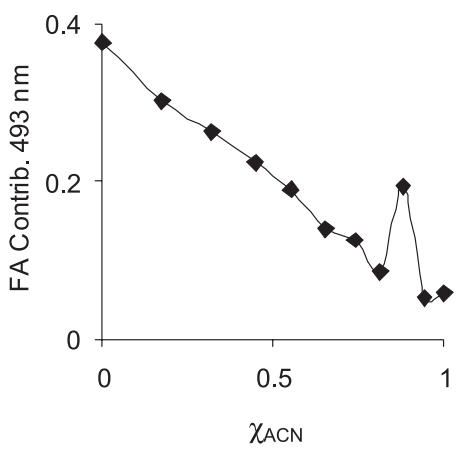

Fluorescence Emission - b

Figure 5. Spectral results of PZ6Br in Ethyl Acetate/Acetonitrile binary mixtures as a function of mole fraction of Acetonitrile. a) band maximum and b) factor analysis calculated contribution of first of two calculated spectral bands; $402 \mathrm{~nm}$ (Abs.) and $493 \mathrm{~nm}$ (Fluor.). 


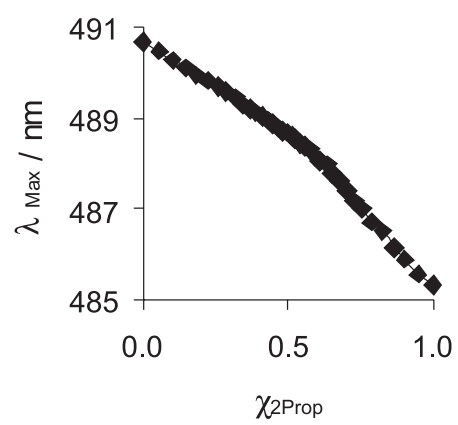

I - a

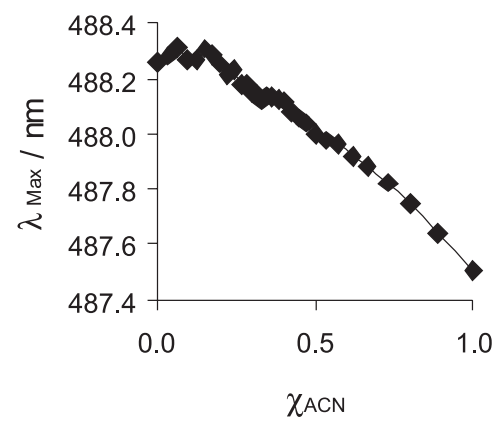

II - a

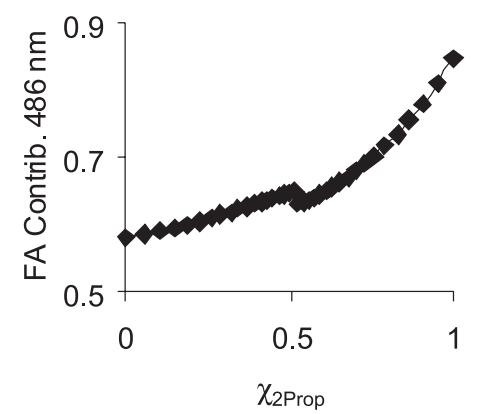

$\mathrm{I}-\mathrm{b}$

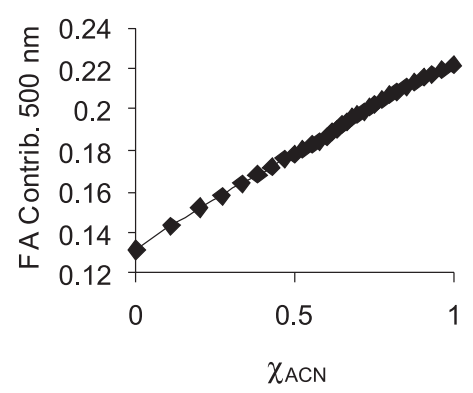

II - b

Figure 6. Absorption spectral results of DPZ5t; I) in Chloroform/2-Propanol binary mixtures as a function of mole fraction of 2-propanol, II) in Ethyl Acetate/Acetonitrile binary mixtures as a function of mole fraction of Acetonitrile. a) band maximum and b) factor analysis calculated contribution of first of two calculated spectral bands; $486 \mathrm{~nm}$ (I-b) and $500 \mathrm{~nm}$ (II-b).

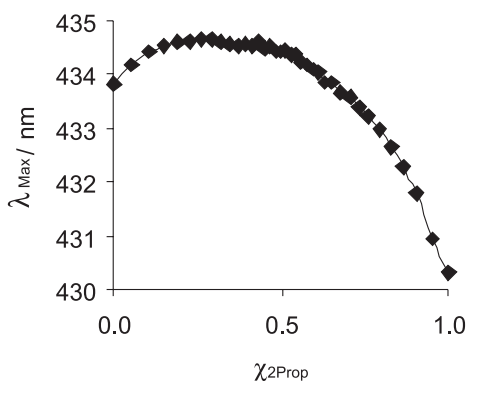

$\mathrm{I}-\mathrm{a}$

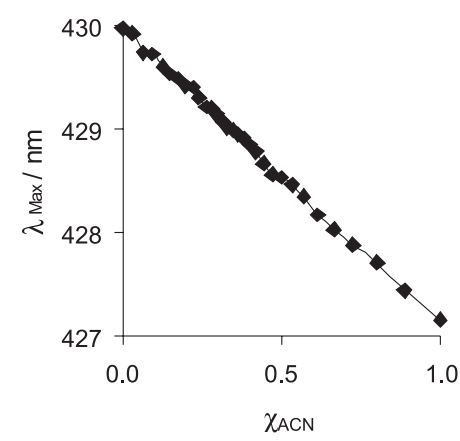

II - a

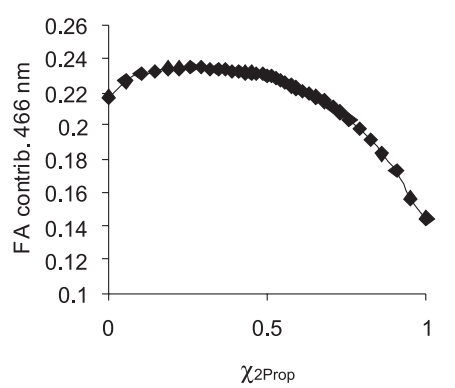

$\mathrm{I}-\mathrm{b}$

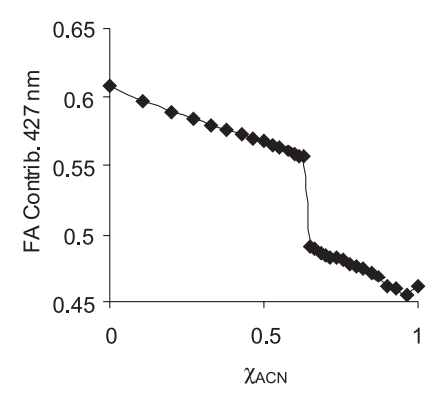

II - b

Figure 7. Absorption spectral results of PZ5; I) in Chloroform/2-Propanol binary mixtures as a function of mole fraction of 2-propanol, II) in Ethyl Acetate/ Acetonitrile binary mixtures as a function of mole fraction of Acetonitrile. a) band maximum and b) factor analysis calculated contribution of first of two calculated spectral bands; $427 \mathrm{~nm}$ (I-b) and $409 \mathrm{~nm}$ (II-b) 
Table 1. Factor analysis calculated spectra maxima and average sum of square deviations

\begin{tabular}{|c|c|c|c|c|}
\hline Dye & Spectroscopy & Solvent pair & $\lambda_{\operatorname{MAX}} / \mathrm{nm}$ & Average ssq \\
\hline \multirow[t]{4}{*}{ DPZ6c } & Absorption & $\mathrm{CHCl}_{3} / 2$-Prop & 434,440 & $1.01 \times 10^{-6}$ \\
\hline & & Eth. Acet./Acetonit. & 436,442 & $1.10 \times 10^{-6}$ \\
\hline & Fluorescence & $\mathrm{CHCl}_{3} / 2$-Prop & 484,498 & $5.90 \times 10^{-7}$ \\
\hline & & Eth. Acet./Acetonit. & 442,476 & $2.78 \times 10^{-7}$ \\
\hline \multirow[t]{4}{*}{$\mathrm{PZ6Br}$} & Absorption & $\mathrm{CHCl}_{3} / 2$-prop & 422,430 & $4.50 \times 10^{-7}$ \\
\hline & & Eth. Acet./Acetonit. & 402,438 & $1.90 \times 10^{-8}$ \\
\hline & Fluorescence & $\mathrm{CHCl}_{3} / 2$-prop & 420,489 & $2.10 \times 10^{-6}$ \\
\hline & & Eth. Acet./Acetonit. & 471,493 & $3.80 \times 10^{-7}$ \\
\hline \multirow[t]{2}{*}{ DPZ5t } & Absorption & $\mathrm{CHCl}_{3} / 2$-prop & 485,497 & $2.40 \times 10^{-6}$ \\
\hline & & Eth. Acet./Acetonit. & 488,500 & $4.04 \times 10^{-7}$ \\
\hline \multirow[t]{2}{*}{ PZ5 } & Absorption & $\mathrm{CHCl}_{3} / 2$-prop & 427,466 & $5.81 \times 10^{-7}$ \\
\hline & & Eth. Acet./Acetonit. & 409,427 & $7.59 \times 10^{-7}$ \\
\hline
\end{tabular}

spectra, to the experimental spectra is the sum of the squares of the differences, summed over all of the points on the spectrum. The average ssq value, taken over every experimental spectrum in any given set, is shown in Table 1 also. A typical (average of the average ssq's) fit is shown in Figure 8.

The dyes used here were chosen because their high fluorescence quantum yield ${ }^{10}$ permitted the use of very low concentrations $\left(<10^{-5} \mathrm{~mol} \mathrm{~L}^{-1}\right)$ of dye, thus guaranteeing that the formation of their dimers could be ignored.

The maxima of the factor analysis calculated spectra are not necessarily contained within the wavelength envelope

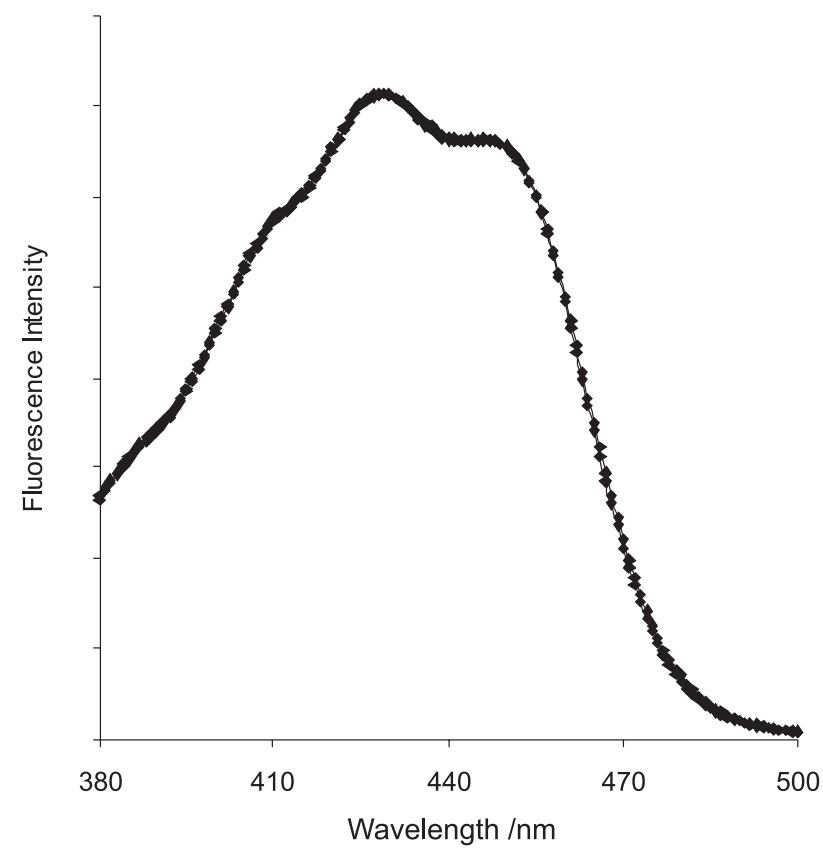

Figure 8. An average $\left(\mathrm{ssq}=7.59 \times 10^{-7}\right)$ fit of calculated (dotted line) and experimental (solid line) spectra, in this case one of the absorption spectra of PZ5 in an ethyl acetate/acetonitrile mixture. of the experimental spectra in the set that generated them. This is probably due to the fact that in non-polar solvents all four dyes used here have various vibrational fine structure peaks ${ }^{7}$ in both the fluorescence band and the lowest energy absorption band. Thus, consistent with this hypothesis, is that the factor analysis calculations are measuring the partial convergence of these peaks as the solvent mixture becomes more polar. This hypothesis also explains why the tendencies in the FA calculated contributions as the fraction of the more polar solvent increases sometimes favor the longer wavelength band and sometimes favor the shorter wavelength band. As the polarity of the solution increases, (i) the wavelength maximum (defined by the principal peak) is red shifted, however, (ii) the peaks merge. If the peak whose contribution decreases is originally red shifted relative to the other, effects $i$ and $i i$, above, oppose one another and the tendency can go in either direction.

Some of the absorption spectral profiles show discontinuities in the middle of the mole fraction scale, in part, probably due to the fact that the curves were constructed by fusing the results of the two separate runs of 0 to 50 volume per cent (see Experimental Section). In the special case of the absorption spectra of PZ6Br in ethyl acetate/acetonitrile mixtures the FA curve is not only discontinuous, but also not monotonic. The discontinuity is probably is due to a small dislocation at the point of connection of the two absorption spectra sets, the discontinuity occurring at that point $\left(\chi_{\mathrm{ACN}}=0.652\right)$ and the small $(1 \mathrm{~nm})$ overall variation in the maxima, corresponding to the resolution of the diode array spectrometer, probably explains the non monotonic behavior. With the exception of the above-cited special case, the "FA Contribution" profiles are both more continuous and monotonic than the " $\lambda_{\text {MAX }}$ " profiles for the fluorescence spectra. In the 
case of the absorption profiles, the two methods seem to be equivalent. In the case of the fluorescence data, this superiority is understood to be due mainly to the ability of the factor analysis method to eliminate a considerable part of the noise from the experimental spectra.

\section{Conclusions}

At this point it would be reasonable to raise the question as to whether the superiority of the FA method proposed here would be expected to be a general phenomenon, or just hold for a limited number of dye/solvent mixture combinations, such as those demonstrated here. Although the method would need to be tested with other dye/binary solvent combinations to give a definitive answer, the evidence presented here would lead one to suspect that this may be a general phenomenon, considering that the FA curves for any one of the given dyes are more linear in the Ethyl Acetate/Acetonitrile binary solvent mixtures than in the corresponding Chloroform/2-Propanol mixtures. This is to be expected because the former mixture involves a smaller polarity variation, therefore should show less preferential salvation (more ideality) and a straighter line.

\section{Acknowledgments}

The authors gratefully acknowledge Prof. Jack Saltiel (Florida State University) for an interesting discussion that gave rise to this project, the Brazilian National Research Council (CNPq) for partial financial support (to T.S.T., R.G.S.S. and I.M.B.), and the Research Management Committee of the University of Newcastle for research visitor support (to I.M.B.).

\section{References}

1. Laha, A. K.; Das, P. K.; Bagchi, S.; J. Phys. Chem. A 2002, 106, 3230 .
2. Khajehpour, M.; Welch, C. M.; Kleiner, K. A.; Kauffman, J. K.; J. Phys. Chem. A 2001, 105, 5372; Silva, M. A. R.; Silva, D. C.; Machado, V. G.; Longhinotti, E.; Frescura, V. L. A.; J. Phys. Chem. A 2002, 106, 8820.

3. Ben-Naim, A.; Cell Biophys. 1988, 12, 255.

4. Agmon, N.; J. Phys. Chem. A 2002, 106, 7256; Wetzler, D.; Chesta, C.; Fernandez-Prini, R.; Aramendia, P. F.; J. Phys. Chem. A 2002, 106, 2390; Molotsky, T.; Huppert, D.; J. Phys. Chem. A 2002, 106, 8525; Fu, K.-X; Li, X.-Y.; Zhu, Q.; Gong, Z.; Lu, S.-Z.; Bao, Z.-M.; THEOCHEM 2005, 715, 157; Rotkiewicz, K.; Rettig, W.; Kohler, G.; Rechthaler, K.; Danel, A.; Grabka, D.; Chem. Phys. 2004, 307, 45.

5. Malinowski, E. R.; Cox, R. A.; Haldna, U. L.; Anal. Chem. 1984, 56, 778; Holden, C. A.; Hunnicutt, S. S.; Sanchez-Ponce, R.; Craig, J. M.; Rutan, S. C.; Appl. Spectrosc. 2003, 57, 483.

6. Pinto, A. V.; Pinto, C. N.; Pinto, M. C. F. R; Emery, F. S.; de Moura, K. C. G.; Carvalho, C. E. M.; Brinn, I. M.; J. Chem. Res. (M) 1999, 2811 (Part 2); Pinto, A. V.; Pinto, C. N.; Pinto, M. C. F. R.; Emery, F. S.; de Moura, K. C. G.; Carvalho C. E. M.; Brinn, I. M.; Heterocycles 1997, 45, 2431; Kooker, S. C.; J. Chem. Soc. 1893, 63, 1376.

7. Carvalho, C. E. M.; Brinn, I. M.; Pinto, A. V.; Pinto, M. C. F. R.; J. Photochem. Photobiol., A 2000, 136, 25.

8. Lawton, W. H.; Sylvestre, E. A.; Technometrics 1971, 13, 617.

9. da Silva, A. S.; Silva, M. A. A.; Carvalho, C. E. M.; Antunes, A. O. C.; Brinn, I. M.; Mangrich, A. S.; Inorg. Chim. Acta 1999, $292,1$.

10. Cabo, J. L.; Faria, H. B.; Portugal, S. G. M.; Silva, M. A. A.; Brinn, I. M.; Photochem. Photobiol. 1999, 69, 664; Carvalho, C. E. M.; Silva, A. S.; Brinn, I. M.; Pinto, A. V.; Pinto, M. C. F. R.; Lin, S.; Moore, T. A.; Gust, D.; Maeder, M.; Phys. Chem. Chem. Phys. 2002, 4, 3383; Lunardi, C. N.; Tedesco, A. C.; Kurth, T. L.; Brinn, I. M.; Photochem. Photobiol. Sci. 2003, 2 , 954; Carvalho, C. E. M.; Silva, M. A. A.; Brinn, I. M.; Pinto, M. C. R.; Pinto, A. V.; Schripsema, J.; Longo, R. L.; J. Lumin. 2004, 109, 207.

Received: December 26, 2008 Web Release Date: September 4, 2009 